balanced judgment can be made than was possible from the previously published literature.

The picture which emerges is a mixed one. There have been the expected difficulties with hardware for measurement and actuation, and reliability was a problem in the earlier machines. The programming and engineering effort has often turned out to be greater and more expensive than was anticipated. Nevertheless, many of the users have decided that computer control already offers benefits which cannot be obtained in any other way. The financial benefits have often been good and the cost of an installation may be recovered in 18 months.

To some extent, however, the favourable economics have been due to an element of subsidy by the computer manufacturers, some of whom have recently been driven out of the field. There also remain unsolved problems in the theory of control - at present our capacity to exploit the great potential power of computers, for control is limited not only by our ignorance about the behaviour of processes, but also by the lack of effective design methods for complex control systems. One may guess that the conference marked the end of an early phase of wideranging experiment and the beginning of $\mathrm{a}_{\mathrm{b}}$ longer, slower, but in the end more solid development.

The papers are divided into four groups, dealing respectively with chemicals and oils, iron and steel, electric power, and various other applications. In the first group are papers by Monsanto (dealing with a multi-computer system, mainly supervisory, on a large site), Imperial Chemical Industries (dealing with direct digital control), B.A.S.F. (direct digital control and optimization) and Shell (basic philosophy). The second group includes papers from the Steel Company of Wales (hot strip mill), Samuel Fox (cut-up line) and the U.S.S.R. (general survey). Power companies are represented by papers from England, France and Italy. In the fourth group are papers on a gas pipe-line network, on paper, cement, railway operation, and transport at an iron-ore mine. In addition to those mentioned, there are papers by a number of eomputer manufacturers on applications with which they have been concerned.

H. H. ROSENBROCK

\section{ARCH DAM STRESS ANALYSIS}

Theory of Arch Dams

Edited by J. R. Rydzewski. (Papers presented at the International Symposium held at Southampton University, April 1964.) Pp. $x+786$. (London and New York: Pergamon Press, Ltd., 1965.) 252s. net.

THEORY of Arch Dams, edited by J. Rydzewski, 1 appears on the spine of this book, the implication being that it is a text-book with a unified approach to the whole subject. In fact, the title ropresents the proceedings of the 1964 symposium at Southampton, which was mainly confined to elastic stress analysis of arch dams under hydrostatic loading. The twelve guineas charged by Pergamon Press seems high when compared with the sixty shillings charged for the proceedings of the conference on "Wind Effects on Building Structures" held at the National Physical Laboratory.

The eighth international congress on "Large Dams", held at Edinburgh in May 1964, brought many eminent people to the United Kingdom; advantage was taken of this to arrange the symposium between them and members of the International Association of Shell Structures, so that the usefulness of shell theory for arch dam analysis could be considered. The resulting papers present a valuable record of present-day research into the orthodox method of analysis and into attempts to apply finite difference, finite element and shell theories to arch dams. The proceedings of the symposium, therefore, do much to acquaint the dam engineer with new methods which might eventually prove useful in dam design.
Dam design is a difficult and fascinating branch of civil engineering; it requires men of wide vision, not only capable of assessing the impact of a dam on the economy of a nation, the hydrological aspects and the geophysical problems, but also possessing the technological skill to choose and design the right kind of dam (earth, rockfill, gravity or arch dam, etc.). Many factors used in the elastic analysis of dams can only be assessed in broad terms, but they can, nevertheless, have effects of over-riding importance on the results. Elastic analysis is thus only one step along the path followed by the engineer in designing a dam. A complete and elegant elastic analysis of arch dam structural behaviour does not yet exist, and it should prove of considerable help when found.

The most widely accepted method of arch dam design is the 'Trial Load Method', which the U.S. Bureau of Reclamation has developed. In essence, the dam is divided into notional arches and cantilevers, and equilibrium is satisfied while compatibility is enforced at the intersections of the arches and cantilevers only. A valuable set of papers by Copen, Beaujoint and others record recent developments in this method. There is the suspicion that sometimes the true modes of structural behaviour may be obscured by enforeing cantilever and arch action.

Probably the best way to improve the elastic analysis of arch dams is to devise techniques for solving the threedimensional equations of elasticity and to take advantage of the ever-increasing facilities offered by digital computers. The difficulty of this is shown by Allen and Windle's solution for the simplest case of a symmetrical circular arch dam of constant thickness in a symmetrical rigid valley. They used finite difference methods with higher order corrections leading to some 450 equations, which have been solved after what must have been considerable effort. My experience is that 450 equations are not enough to represent the three-dimensional stress field with adequate accuracy, and that $2,000-5,000$ equations are needed, which in turn requires special computer techniques. Otter's paper on dynamic relaxation describes one such computer technique.

A very powerful group of papers by Parme, Herzog, Tottenham and others apply the shell theories with elegance. Modes of structural behaviour other than arch/ cantilever action are permitted; however, the shell theories are approximate and impose their own limitations; for example, the Kantorovitch theory does not allow any upstream deflexion. A more serious aspect, though, is the limitation of the validity of the theories to the thin zones of arch dams.

Finite element methods have been used most successfully in aireraft design; papers by Clough and Zinkiewiez give lucid accounts of the first attempts to apply the methods to arch dams.

Rocha has contributed a most valuable review paper, and the problems of rock mechanics and concrete properties are introduced by Stagg and Newman respectively. This group of papers is a timely reminder of other gaps in our knowledge, such as the need for a good failure criteria for concrete under tri-axial states of stress including uplift pressures.

A. C. CASSELI

\section{ASPECTS OF OXYGEN THERAPY}

\section{Hyperbaric Oxygenation}

Proceedings of the Second International Congress, Glasgow, September 1964. Edited by I. McA. Ledingham. Pp. xi+472. (Edinburgh and London: E. and $\mathrm{S}$. Livingstone, Ltd., 1965.) $70 s$.

7 HE second international congress on "Hyperbaric Oxygenation" was held in Glasgow during September 1964 ; it was very appropriately dedicated to Sir Charles Illingworth. 